\title{
Attrition and Retention Practices in Multi National Companies (MNCs) in India
}

\author{
Dr. A. Roqsana Taher \\ M.Com., M.B.A., M.Phil., Ph.D., Research Supervisor, Mettur Dam, Salem District, India
}

\begin{abstract}
There are many different ways for a company to lose employees, most of which are typically taken into account to ensure that the organization is able to operate efficiently. Attrition refers to the loss of employees due to reasons other than firing and other employer-initiated events. This means that an employer has no direct control over how many personnel are lost to employee attrition. Retirement is one major cause of employee attrition, and since people tend to retire around a specific age this is a factor that can be accounted and planned for. Other causes of employee attrition, such as personnel who quit due to prolonged illness, dissatisfaction with the company, or other reasons, can be more difficult to estimate. There is no universal attrition management solution for every company. Each organization has to build its own motivation system based on compatibility between organizational and individual goals. Nevertheless, most of the approaches and solutions described above have been successfully implemented by a great number of companies operating in India. The general conclusion is that internal motivation factors in India appear to be more effective than the classical external ones. Such motivators as challenging work, family benefits, learning opportunities, the chance to go abroad, and career advancements were found to be much more significant than monetary compensation.
\end{abstract}

Keywords: Attrition, Employees, Motivation, Organization, Retention.

\section{Introduction}

Employers generally consider attrition a loss of valuable employees and talent. However, there is more to attrition than a shrinking workforce. As employees leave an organization, they take with them much-needed skills and qualifications that they developed during their tenure. On the other hand, junior professionals with promising qualifications can then succeed into higher level positions or business owners can introduce more diversity in experience or expertise. Accordingly, there are benefits and disadvantages to attrition. In other words Employee attrition refers to the loss of employees through a number of circumstances, such as resignation and retirement. The cause of attrition may be either voluntary or involuntary, though employer-initiated events such as layoffs are not typically included in the definition. Each industry has its own standards for acceptable attrition rates, and these rates can also differ between skilled and unskilled positions. Due to the expenses associated with training new employees, any type of employee attrition is typically seen to have a monetary cost. It is also possible for a company to use employee attrition to its benefit in some circumstances, such as relying on it to control labor costs without issuing mass layoffs.

\section{Attrition and motivation: Retaining staff in MNCs in India}

Many international companies in India struggle to find and keep the right people for the job. High attrition rates cause unforeseen expenses and sometimes even crush the entire Indian business venture. Motivating workers becomes a vital part of the business. But how do you motivate the Indian employee?

We have all become accustomed to the colorful and optimistic descriptions of present-day India. Nowadays, India is seen as a country of opportunities, a booming market, one of the best performing economies in the world, a nation on the move.

Since the onset of globalization in India during the early 1990s, liberal economic reforms of the government led to a steady flow of investments, provided competitive advantages to attract major multinational corporations (MNCs), and eventually turned the country into the world outsourcing center. In 2005, India controlled more than 40 percent of the global offshore outsourcing market for software and back-office services, with revenues of US $\$ 17.2$ billion. By the end of 2008, as many as 2,279 MNCs in both manufacturing and service-sector industries set up more than 3,300 offices in India. In spite of the global financial crisis, India not only manages to stay afloat but also keeps on a rather active process of development.

While offering a rich set of advantages, India is equally famous for the great amount of challenges, which it delivers to foreign companies. Experience shows that a considerable number of MNCs face serious problems while establishing and running a business in India. For example, statistics show that as many as 70 percent of South Korean companies working in India fail.

\section{Reasons for Attrition}

It is not easy to find out as to who contributes and who has the control on the attrition of employees. Various studies/survey conducted indicates that everyone is contributing to the prevailing attrition. Attrition does not happen for one or two reasons. The way the industry is projected and speed at which the companies are expanding has a major part in attrition. The specific reasons for attrition are varied in nature and it is interesting to know why the people change jobs so quickly. Even today, the main reason for changing jobs is for higher salary and better benefits. While attrition cannot be attributed to employees alone, let us look at some of the possible reasons 


\section{International Journal of Science and Research (IJSR) \\ ISSN (Online): 2319-7064 \\ Index Copernicus Value (2013): 6.14 | Impact Factor (2015): 6.391}

Organizational matters: The employees always assess the management values, work culture, work practices and credibility of the organization. The Indian companies do have difficulties in getting the businesses and retain it for a long time. There are always ups and downs in the business. When there is no focus and in the absence of business plans, non-availability of the campaigns makes people to quickly move out of the organization.

Working environment: Working environment is the most important cause of attrition. Today's Gen Next employees expect a professional approach and an international style working environment. They expect a friendly and learning environment. Employees look for freedom, good treatment from the superiors, good encouragement, friendly approach from one and all, and good motivation.

Job matters: No doubt the jobs today bring lots of pressure and stress is high. The employees often switch jobs if there is too much pressure on performance or any work related pressure. It is quite common that employees are moved from one process to another. They take time to get adjusted with the new processes while few employees find it difficult to adjust and consequently leave. Monotony sets in very quickly and this is one of the main reasons for attrition. Job hopping is very common among youngsters who look at jobs as being temporary. An other commonly looked option is to move to such other process where there is little or no pressure of sales and meeting service level agreements (SLA). The employees move out if there are strained relations with the superiors or with the subordinates or any slightest discontent.

Salary and other benefits: Moving from one job to another for higher salary, better positions and better benefits are the most important reasons for attrition. The salaries and benefits offered by MNCs are generally higher than their Indian counterparts. The employees expect salary revision once in 4-6 months and if not they move to other organizations.

Personal reasons: The personal reasons are many and only few are visible to us. They vary widely from getting married to relocating for health/ family reasons. The next important personal reason is going for higher education. Health is another aspect, which contributes for attrition.

Poaching: The demand for trained and competent manpower is very high. Poaching has become very common. The rise in the number of placement agencies has led to a boom in poaching. Most of the organizations have employee referral schemes and this makes people to spread message and refer known candidates from the previous companies and earn too.

\section{Attrition - a major issue}

A number of research projects in the last five years show that one of the most common issues leading to failure or unexpected expenses is the fact that almost every foreign company fails to retain qualified personnel in India. Statistics are impressive. According to the recent study of the Chambers of Commerce of India, attrition in the booming IT/ITES sector averages 25 - 30 percent. The average personnel turnover rate in the business process outsourcing (BPO) sector even hit a high of 30 - 35 percent.

The business that probably suffers most from attrition are call centers. A personnel turnover rate in Indian call centers has become a legend, with an average of around 30 - 40 percent and extreme cases of 80 percent. Growing attention to the issue and the global economic slowdown reduced the average figure to 24 - 30 percent, but this still has a significant impact on costs and quality.

A number of experts claim that the costs associated with attrition are so high in India that they can override the benefits of lower wages. Both smaller and bigger businesses are facing the same problem. A number of companies in the BPO sector have already moved their offices from India after staff turnover rates wiped away any potential cost savings. One of the major concerns that MNCs' human resources managers express in India is that people do not stay long enough to be taught or to learn the job. This can have a disastrous impact on a company's success. Moreover, managing attrition is often the route to survival in presentday India.

\section{Retaining Staff}

It would be wrong to say that only MNCs and foreign businesses fail to keep personnel. Turnover of staff is a significant concern at many national and multinational corporations in many parts of the world. Staff attrition and absenteeism cause significant costs for most local Indian organizations as well. Almost every sector in India is facing high rates of attrition. It is a universal phenomenon and almost no industry or region is devoid of it. Nevertheless, its degree in MNCs operating in India is considerably higher than in the local, traditional Indian companies.

The main question is why experienced international companies cannot retain qualified personnel in India. Probably, the first mistake that a number of companies make, is to assume that a company in India can be run just (or almost) like a company in its home country. Homecountry HR approaches can appear to be less effective in India than in any other region of the world.

Motivation procedures are a major factor to help retain staff. However, motivation is not achieved with the same methods and procedures throughout the world. The first mistake foreign companies can make in India, is to use the same methods of motivation in order to retain Indian personnel as they use in their home countries.

\section{Retention Strategies}

Retention of efficient employees is one of the most critical challenges faced by many corporates worldwide and our Indian companies are no exception to this phenomenon. The HR managers have been facing a tough time finding a suitable replacement with required experience and ability, to fill up the vacancies created on account of exit of key employees. The reasons can be varied like shortage of skilled manpower, growth in opportunities as a result of economic reforms and liberalized policies pursued by 


\section{International Journal of Science and Research (IJSR) \\ ISSN (Online): 2319-7064 \\ Index Copernicus Value (2013): 6.14 | Impact Factor (2015): 6.391}

successive governments at the Centre. Attrition level can also be more due to rigid and unpopular HR policies pursued by the corporate. Company managements are increasingly concerned about retaining qualified experienced managers and lot of debate has taken place about the increasing trend in employees' attrition, more particularly in knowledgebased industry like software and mutual fund industry. The idea of employee stock option plans ESOP program is to align the individual with corporate goals. Some of the leading AMCs /MNCs are sending their employees to reputed institutes in foreign countries to upgrade their skills as well as to reward and motivate the performing employees further. Some of the leading MNCs and financial institutions have also made arrangement with local management institutes to design tailor-made courses for training their employees.

\section{Different hierarchies of values}

In spite of the fact that practically all nations of the world share a similar set of values, intercultural experts nowadays claim that the importance and the hierarchy of these values vary in each particular society (or culture). A different hierarchy of values naturally implies variations in the methods used in order to retain and motivate staff. Reducing attrition involves a thorough understanding of the human psyche.

Thus, methods need to be cultural-specific. Indian cultures are in several ways different not only from Western cultures, but also from neighboring Oriental and Middle-Eastern ones. This in turn influences business success and productivity of new entrants in this market and requires culture-specific, Indian culture-based methods of motivation. In order to better understand how to motivate employees, it is crucial to first understand how their motivation works.

\section{Methods of Motivation}

According to the classical theory of Abraham Maslow, people are motivated by unmet needs. The famous Maslow's hierarchy of needs includes:

- Psychological, survival needs

- Safety and security needs

- Social needs of acceptance

- Esteem and acknowledgement needs

- Self-actualization and self-development needs

In management theory, once one of these needs is met, a person will start to develop the next need. The challenge of an international HR manager is to understand the types of needs in a particular culture.

\section{Money as a Motivator}

The traditional method of motivating employees in the Western business culture has been to use extrinsic motivation such as pay rises, bonuses, and promotions.

A recent study revealed that employees (especially those in non-Western cultures) leave not only for compensation reasons. It is no surprise that money is an important factor, but there are many other reasons for an employee's decision to leave. In fact, in the current Indian business environment, increasing the basic salary hardly reduces turnover. In a country with a comparably low cost of living, satisfaction with the salary tends to be reached more quickly. Employees look beyond the money factor and new aspects become crucial.

\section{A long term perspective including the family:}

Safety and acceptance needs are the ones to be satisfied next. According to a recent survey, consistent with the Indian traditional collectivist and relations-oriented culture, as many as 70 percent of employees see job security and emotional comfort as the major elements of motivation. Traditional Indian companies often play the role of a family extension for their staff. They provide a feeling of belonging, build personal relations, and offer long-term (often life-long) contracts.

Besides, research shows that those organizations that appear to be successful on the Indian market often include employees' families into the company life. Family in India plays a crucial role in the life of an individual. A family decision can change the career path of a young professional and make him abruptly change his or her job. All this translates into huge losses for the company, which invests a lot of money into training them. That is why one of the reasonable solutions for a company would be to involve the families of employees into the company life. Basic things such as family, sport and recreation events, small presents, and specific types of financial support will do the job.

\section{Enabling personal development}

Ideally, the next step of the motivation policy should meet the esteem and acknowledgement needs. These are highly important in such a hierarchical society as India. A higher position in this culture means status and respect. It often does not automatically imply elements of extra responsibility and additional duties typical for the Western attitude, but rather means additional benefits, better work conditions, and respect.

This explains the concern for individual development and career advancement. An Indian employee, as any other employee, is keen to know his or her career opportunities and path in the company. A career development program could be one of the solutions for an effective motivation policy.

Another factor closely connected with career growth are the learning opportunities available. Knowledge and experience are seen as status factors and lead to a higher degree of respect and acknowledgement. According to research, companies providing both technical and soft skills trainings appear to be more attractive and succeed more in their retention policies.

\section{Conclusion}

It can be concluded that most important reason of attrition is Compensation, because plenty of opportunities are there in the market for experienced, well qualified employees if they switch over to other companies and they will pay more. 
There are many push, pull and personal factors are involved and initiating the thought of turnover among employees. Organization should be alert and frame some necessary strategies to reduce attrition so that they can reduce the expenditure of employees for recruitment, training and development.

In order to find and retain the right people for the job, international businesses in India need to redesign their reward and recognition packages according to the local culture. There is no universal attrition management solution for every company. Each organization has to build its own motivation system based on compatibility between organizational and individual goals.

Nevertheless, most of the approaches and solutions described above have been successfully implemented by a great number of companies operating in India. The general conclusion is that internal motivation factors in India appear to be more effective than the classical external ones. Such motivators as challenging work, family benefits, learning opportunities, the chance to go abroad, and career advancements were found to be much more significant than monetary compensation.

\section{References}

[1] Abassi SM, Hollman KW(2000). "Turnover: THE REAL BOTTOM LINE" Public Personnel Management, 2(3):333-342.

[2] Denvir, A. \& McMahon, F. (1992) „Labour Turnover in London Hotels and the Cost Effectiveness of Preventative Measure ${ }^{\text {ee }}$ International Journal of Hospitality Management, Volume 11, No. 2, pp 143 154.

[3] Firth L, David J Mellor, Kathleen A Moore \& Claude Loquet (2007). "How can managers reduce employee intention to quit?" J. manage.Psychol. 19 (2): 170-187.

[4] Forbes, A. (1971) „Non-parametric Methods of Estimating the Survivor Function ${ }^{e e}$, The Statistician, Volume 20, pp $27-52$.

[5] Goleman(2001), Boyatzis, Richard; McKee, Annie. Primal Leadership: The Hidden Driver of Great Performance, Harvard Business School Press. ISBN 9781-57851-486-1. 